\title{
Rock fisher behaviours and perceptions regarding drowning risk assessed by direct observation and self-report: A public awareness campaign evaluation
}

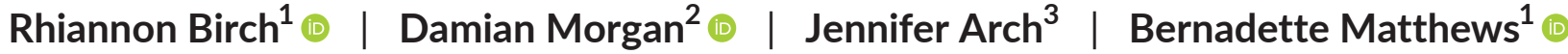

\author{
${ }^{1}$ Risk and Research Services, Life Saving \\ Victoria, Port Melbourne, Victoria, \\ Australia \\ ${ }^{2}$ College of Business, Law \& Governance, \\ James Cook University, Douglas, \\ Queensland, Australia \\ ${ }^{3}$ Media and Communications, Life Saving \\ Victoria, Port Melbourne, Victoria, \\ Australia \\ Correspondence \\ Damian Morgan, College of Business, Law \\ \& Governance, James Cook University, \\ Douglas, QLD 4814, Australia. \\ Email: damian.morgan@jcu.edu.au \\ Funding information \\ The project was funded by Department of \\ Environment and Primary Industries (now \\ Department of Environment, Land, Water \\ and Planning) recreational fishing large \\ grants program
}

\begin{abstract}
Issue addressed: Participants engaged in rock fishing are at risk of drowning. Following coronial investigation of fatalities, a 3-year safety campaign targeting rock fishers was developed in Victoria, Australia. Key campaign messages were wearing lifejackets, not fishing alone, and checking sea and weather conditions. The reported study provides results from a campaign evaluation.

Methods: Evaluation by self-report and direct observation of safety attitudes and behaviours was undertaken pre- and during campaign. Data collections were as follows: (a) online survey of rock fishers recruited from panels, social media and rock fishing networks ( $n=350$ ) and (b) rock fisher direct observation and self-report at selected Victorian rock fishing platforms ( $n=282 ; n=58$, respectively).

Results: Safety message recall was reported by $51.7 \%$ of rock fishers surveyed online though far fewer recalled campaign key messages. No effect on key safety behaviours or attitudes were detected for fishers on platforms during campaign. Never wearing a lifejacket was reported by $31.8 \%$ online, $60.3 \%$ at platforms and observed for $97.4 \%$. From direct observation, most participants did not fish alone and checked conditions on arrival. Conclusion: Campaign evaluation measures showed mixed outcomes. Irrespective, most rock fishers carry high drowning risk through failure to wear lifejackets. Legal mandating of lifejackets for identified high-risk platform is being introduced for Victoria, although careful evaluation is required to detect unanticipated outcomes. Informing future campaign evaluation, complementary methods highlight likely bias in self-reporting through faulty recall or social desirability.
\end{abstract}

So what?: Future campaigns require innovative or novel design, over longer duration, to capture attention and change rock fisher behaviours.

KEYWORDS

behaviour change, evaluation methods, injury

\section{INTRODUCTION}

Rock fishing is a popular recreational activity occurring on Australian coastlines. Intrepid anglers commonly seek out prime fishing locations including difficult to access wave-battered rocky shore platforms. Dynamic coastal processes present environmental hazards from waves overtopping shore platforms, potentially washing rock fishers into the sea. ${ }^{1}$ The risk of water entry is exacerbated where platforms are 
sub-horizontal rather than gently sloping with a seaward cliff adjacent to deep water and exposed to higher wave energy. ${ }^{1} \mathrm{~A}$ recent study reported a $46.3 \%$ increase in drowning at rock locations based on 3-year average comparison periods (2004-2007 and 2017-2020). ${ }^{2}$

Unsurprisingly, rock fishing is among the most dangerous aquatic sports in Australia. ${ }^{3}$ From 2004-2017, an annual average of 12 rock fisher drowning deaths have been reported. ${ }^{4}$ Comparable data for 2000-2012 reports 13 rock fisher drowning deaths in Victoria., ${ }^{5,6}$ Of Victorian cases, $85 \%$ were aged 35 to 59 years with $85 \%$ from culturally and linguistically diverse (CALD) backgrounds (majority Chinese or Vietnamese). No decedents wore lifejackets. A nonfatal injury study for the period 2002-2009 revealed 33 rock fisher hospitalisations in Victoria. ${ }^{5}$ Of these, 29 (88\%) were injured through falling with 24 (73\%) sustaining bone fracture.

Wearing an activity-appropriate lifejacket during aquatic activities is an effective drowning countermeasure. ${ }^{7}$ Contrasting with boaters on Victorian waterways, rock fishers have no current legislative requirement to wear lifejackets. ${ }^{8}$ A 2009 Victorian coronial inquest for three rock fishing fatalities recommended that wearing a lifejacket while rock fishing should feature prominently in stakeholder communications and that CALD communities be targeted in community education.?

Rock fisher drownings and coronial recommendations prompted a 3-year Victorian State Government funded safety campaign targeting safety practices and injury prevention. The study reported here evaluated this campaign using multiple data collection methods.

\section{1 | Previous rock fisher safety campaigns}

Rock fisher safety campaigns reported for Australia and New Zealand have incorporated education strategies and workshops to improve knowledge of drowning risk and safe behaviour promotion. ${ }^{3,10}$ However, evidence regarding effectiveness of rock fishing safety interventions and public awareness campaigns remains sparse. ${ }^{5,11,12}$ One study from New Zealand reported campaign effectiveness evidence for lifejacket wearrates. The 10-year West Coast Fisher Safety Project provided on-site education at high-risk locations by trained bilingual field officers. ${ }^{13}$ Intervention included a fishing safety program assisting rock fishers to identify and manage risks on rugged coastlines supplemented by media promotion and static displays. Self-report surveys of rock fishers' safety knowledge, beliefs and behaviours identified a ten-fold increase (from 2006 at $4 \%$ to 2015 at $40 \%$ ) in self-reported lifejacket wear (often/always).

\section{2 | The Victorian rock fisher safety campaign}

Developing the Victorian rock fisher safety campaign was informed by previous campaigns in New South Wales (NSW) tailored for a Victorian context. $^{5,10}$ The campaign aimed to raise awareness to change safety behaviours among Victorian rock fishers as the primary target audience through focussed communication and promotional strategies. The overall campaign goal was to reduce rock fishing fatalities in Victoria.

Campaign design and key messages were informed and devised through consultations with industry experts and rock fishing participants, with particular focus on CALD communities. Local rock fishing experts first reviewed NSW campaign materials, messaging and imagery (including logos) and then updated where needed for a Victorian audience. Rock fisher focus-groups held with adults from Chinese $(n=6)$ and Vietnamese $(n=6)$ backgrounds identified rock fishing safety behaviours and attitudes and comprehension of proposed safety messages. Also gauged were preferences for water safety message communications regarding creative forms and media channels. A separate forum consulted industry stakeholders comprising Victorian and Australian fishing associations, government entities including Fisheries Victoria (now Victorian Fisheries Authority) and Victoria Police.

Collected information apprised an online survey of 127 Victorian rock fishers targeting particularly persons from CALD backgrounds plus 33 partners, family or friends considered behavioural influencers (rock fisher data also provided pre-campaign baselines for the current study). Survey participants assessed the efficacy and reach of creative conceptualisations for proposed safety messages, delivery methods and media preference. Findings were translated to key campaign messages: wear a lifejacket when rock fishing; never fish alone and check the sea and weather conditions before fishing.

A communications plan delivered campaign messages (December 2013-May 2015) using the following:

- Carpark and roadside billboards targeting key rock fishing locations;

- advertising through radio, print and social media plus public relations activities targeting Chinese and Vietnamese media consumers;

- appointment and training of rock fishing ambassadors promoting safety and

- delivering two rock fishing safety workshops for Chinese $(n=23)$ and Vietnamese $(n=28)$ fishers.

Campaign materials are shown in Figure 1. The campaign season ran each year (13-14 and 14-15) from December (summer start) to April (end of Easter holiday period). Media monitoring estimates indicate campaign reach of more than 750,000 people, or 16.2 percent of the Victorian adult population in 2013-2014. ${ }^{14}$

\section{3 | Study aim}

The current study measured the Victorian rock fisher safety campaign effectiveness through assessment of rock fisher attitudinal change and safety behaviour adoption.

\section{2 | METHODS}

\subsection{Study design}

Evaluation data were collected pre- and during campaign over a 3-year period (2012-2015) using an online survey plus self-reports and direct rock fisher observations for those using selected rock 
Carpark billboard

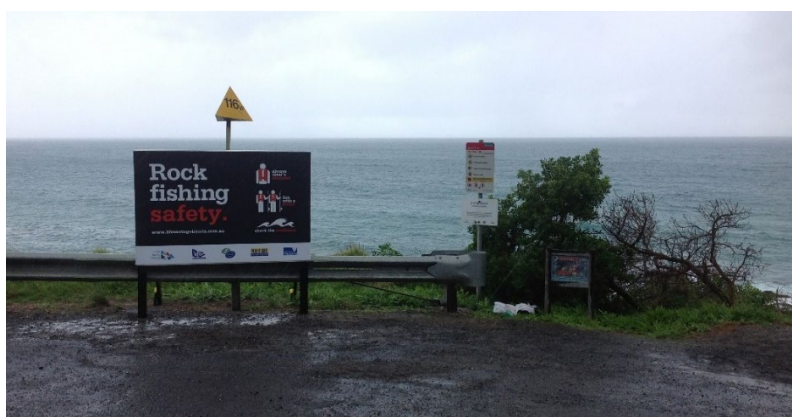

Print - English version

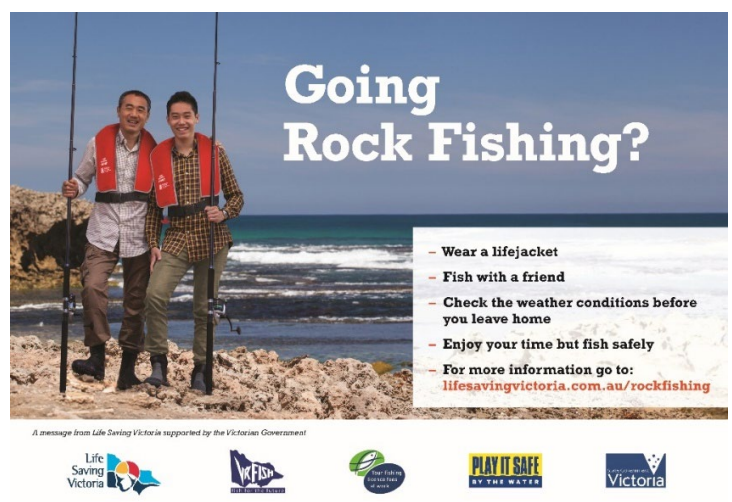

FIGURE 1 Rock fishing campaign material examples

platform locations in Victoria. Specifically, pre-campaign online data collection was in November 2012 and during-campaign on April-May 2014 and April-May 2015. Pre-campaign data collection for platform users was January 2013-June 2013, and duringcampaign, December 2013-November 2014 (campaign year 1) and December 2014-May 2015 (campaign year 2). Postcampaign evaluation was not technically possible given that campaign elements continued after May 2015 and additional funds for data collection were not available. Human research ethics approval was granted by Monash University and Federation University Human Research Ethics Committees - Projects CF13/276 and E14-015, respectively; a national parks research permit was provided by the Department of Environment and Primary Industries (No. 10006774).

\section{2 | Instruments}

\subsection{1 | Online rock fisher questionnaire}

Online evaluation data were collected from Victorian rock fishers and family members. As Victorian rock fishers comprise a small and difficult to access population, a convenience sampling strategy accounted for CALD backgrounds. Recruitment was via a panel-data provider, direct community engagement sessions and indirectly through survey links disseminated by stakeholder groups (ie fishing
Mobile billboard

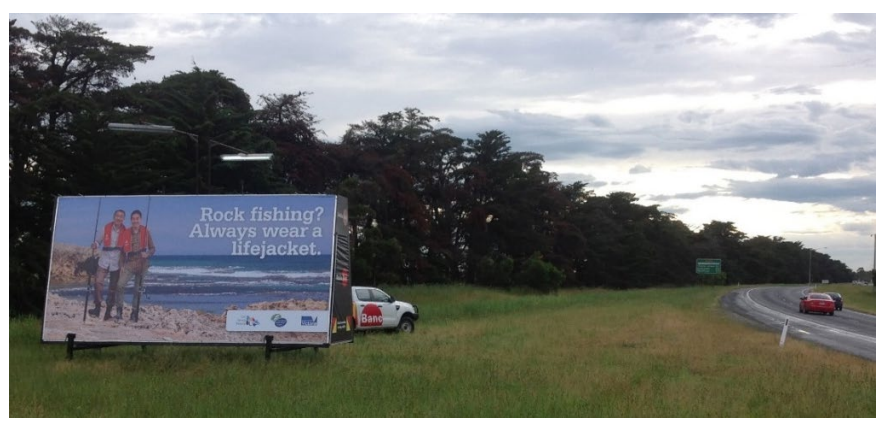

Print - Vietnamese version

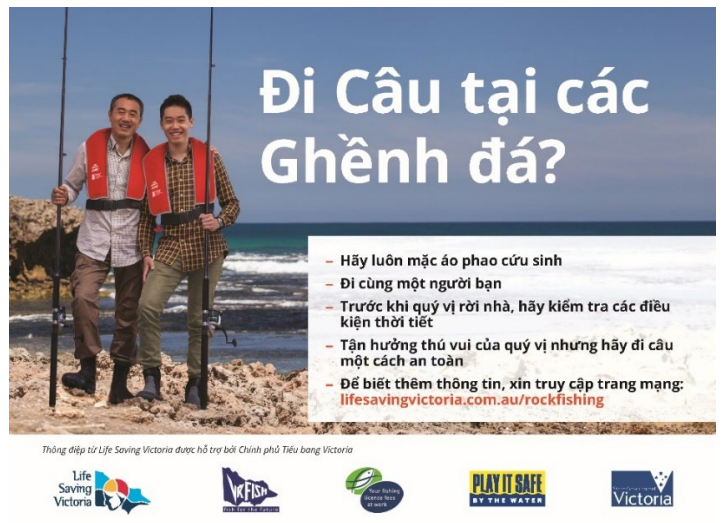

organisations). The online questionnaire measured campaign message recall plus rock fisher safety attitudes and behaviours. This was available in English, Simplified Chinese and Vietnamese.

\subsection{2 | Coastal rock fishing questionnaire}

Self-reports from rock fishers were collected at access points to coastal rock platforms by bilingual research assistants (speaking English, Mandarin and/or Cantonese, and/or Vietnamese). Self-reported ratings comprised rock fishing experience; water competency; perceived rock fishing risk and safety awareness; fishing behaviours and, after campaign launch, message recall. Questionnaires were provided in English, Simplified Chinese and Vietnamese with language selected based on the country of birth data from rock fisher fatalities.

\subsection{3 | Coastal platform direct observation}

Piloting (December 2012) indicated the suitability of direct observation methods for rock fishers using rocky platform locales along Victoria's coastline. Seven platforms were selected for rock fishing popularity and known drowning incidents (Phillip Island - Pyramid Rock and Punchbowl; Mornington Peninsula - Cape Schanck and 
Blowhole; Western coastline - Eastern view, Lorne and Wye River). Direct observation by a single observer with binoculars of all rock fishers on rocky platforms, taken from a safe location, were conducted by trained researchers on 28 week-end days from January 4, 2013 to May 16, 2015 across all seasons. Observations were made at two sites per day, one in the morning and one in the afternoon, each for 90 minutes. Each 90-minute observation period overlapped with mid-tidal range (either rising or falling). Person and situation variables recorded were equipment (eg lifejacket), clothing (eg shoe type) and environmental variables (eg wind strength). Safety-related behaviours recorded included turning one's back on the sea, fishing alone and checking conditions prior to fishing. Checking conditions was judged by rock fishers observing the ocean and location before equipment set-up. The time spent checking conditions was recorded. Observer training was conducted prior to attendance onsite with support of visual examples of light clothing (eg short sleeves, thin cloth) and heavy clothing (jeans, bulky jackets or waders). Instruments used for platform recordings are available as supplementary files.

\subsection{Data analysis}

Data were analysed using SPSS. ${ }^{15}$ Self-reported and direct observation intervention data collected consistent with campaign seasons were grouped for pre-campaign and during campaign. Duringcampaign data collected December 2013-November 2014 and December 2014-May 2015 were pooled (as reported below, no statistical differences were found between subgroupings across campaign year 1 and 2 on safety attitudes or behaviours). Categorical data are reported in frequencies and percentages. Mean and standard deviation (SD) are reported for numeric data. Statistical tests appropriate to the data were chi-square, Fisher's exact test, independent-sample t-test, Mann-Whitney $U$ test or Kruskal-Wallis $(P<.05)$ with effect sizes reported for statistically significant results using the VassarStats online calculators. ${ }^{16}$

\section{$3 \mid$ RESULTS}

\section{1 | Sample demographics and platform behaviours}

For online survey participants combining pre- and during-campaign samples ( $\mathrm{N}=835), 350(41.9 \%)$ identified as rock fishers (127, $36.3 \%$ pre and $223,63.7 \%$ during). For this grouping only, $69.4 \%$ were male. For age, $23.7 \%$ were $\geq 60$ years and $18.3 \% 18-29$ years. Approximately one-third (29.1\%) of respondents were born outside Australia with $21.1 \%$ speaking a language other than English at home. For these variables, no statistical difference was found between pre- and during campaign.

Table 1 lists rock fisher demographic characteristics surveyed at rock platforms $(n=58)$. Respondent profiles taken pre- $(2012-13)$
TAB LE 1 Self-reported rock fisher demographics using rock platforms $(n=58)$

\begin{tabular}{|c|c|c|c|c|c|}
\hline & \multicolumn{2}{|c|}{$\begin{array}{l}\text { Pre-campaign } \\
(\mathrm{n}=27)\end{array}$} & \multicolumn{2}{|c|}{$\begin{array}{l}\text { During } \\
\text { campaign } \\
(\mathrm{n}=31)\end{array}$} & \multirow[b]{2}{*}{ Test statistic } \\
\hline & $\#$ & $\%$ & $\#$ & $\%$ & \\
\hline \multicolumn{6}{|l|}{ Gender } \\
\hline Male & 26 & 96.3 & 30 & 96.6 & n.s. \\
\hline Female & 1 & 3.7 & 1 & 3.4 & \\
\hline \multicolumn{6}{|l|}{ Age } \\
\hline $18-29$ years & 7 & 25.9 & 5 & 16.1 & n.s. \\
\hline 30-39 years & 10 & 37.0 & 13 & 41.9 & \\
\hline $40-49$ years & 7 & 25.9 & 7 & 22.6 & \\
\hline $50-59$ years & 3 & 11.1 & 4 & 12.9 & \\
\hline 60 years and over & 0 & 0.0 & 2 & 6.5 & \\
\hline \multicolumn{6}{|l|}{ Region of birth } \\
\hline Oceania $^{a}$ & 5 & 18.5 & 13 & 43.3 & $P=.04, \nu=0.4$ \\
\hline Asia, South Asia & 15 & 55.6 & 12 & 40.0 & \\
\hline $\begin{array}{c}\text { Central/South } \\
\text { America }\end{array}$ & 3 & 11.1 & 0 & 0.0 & \\
\hline Europe & 1 & 3.7 & 4 & 13.3 & \\
\hline Africa, Middle East & 3 & 11.1 & 1 & 3.3 & \\
\hline \multicolumn{6}{|c|}{ Language spoken at home } \\
\hline English & 11 & 40.7 & 25 & 80.6 & $P<.01, \nu=0.4$ \\
\hline Other & 16 & 59.3 & 6 & 19.4 & \\
\hline \multicolumn{6}{|l|}{ Time in Australia } \\
\hline Whole life & 6 & 22.2 & 13 & 41.9 & n.s. \\
\hline Over 9 years & 13 & 48.1 & 14 & 45.2 & \\
\hline 5 to 9 years & 5 & 18.5 & 2 & 6.5 & \\
\hline 1 to 4 years & 3 & 11.1 & 2 & 6.5 & \\
\hline
\end{tabular}

Note: n.s. - not statistically significant.

${ }^{a}$ Including Australia and New Zealand.

and during- (combined 2013-14 and 2014-15) campaign were broadly similar excepting speaking English at home and Oceania region of birth being overrepresented during-campaign. Table 2 lists rock fisher estimated gender, age and observed behaviours for those directly observed on platforms ( $n=282$ ). The majority were male with a higher proportion during-campaign. Most persons observed were engaged in rock fishing although pre-campaign there was a higher relative proportion of persons accompanying rock fishers (Table 2).

\subsection{Campaign recall for online and rock platform samples}

Rock fisher responses for the online survey $(n=350)$ revealed that $51.7 \%$ had seen or heard advertising or information about rock fishing safety in the previous 12 months with no statistical differences between pre-and during campaign. Unprompted recall captured 
during campaign for rock fishers online on three key safety messages had 7.2\% identify wearing of lifejackets, 9.4\% not fishing alone and $4.9 \%$ check weather conditions. For 31 rock fishers surveyed adjacent to platforms (during-campaign), unprompted recall of rock fishing safety advertising or information for the prior year was $67.7 \%$. Most frequently cited advertising sources were public media (newspapers, television, radio, websites; $52.4 \%$ ), signage at rock fishing sites (42.9\%) and roadside billboards (14.3\%).

\section{3 | Rock fisher safety attitudes}

Table 3 lists rock fisher safety self-reported attitudes provided adjacent to rock platforms. The table indicates general agreement that rock fishing carries real risk requiring measures for personal protection. On average, respondents agreed on recommending others wear a lifejacket when rock fishing, never to go rock fishing alone, importance of checking surf, tides and weather conditions beforehand, and that being swept off rocks while fishing is likely to result in drowning. No statistical differences were found between pre- and during campaign (or for the during-only groupings between campaign year 1 and year 2). For all listed measures (Table 3), no statistically significant differences were found between those able to recall safety campaign information and others.

TABLE 2 Person and situation variables for rock fishers observed on rock platforms $(n=282)$

\begin{tabular}{|c|c|c|c|c|c|}
\hline & \multicolumn{2}{|c|}{$\begin{array}{l}\text { Pre- } \\
\text { campaign } \\
(n=105)\end{array}$} & \multicolumn{2}{|c|}{$\begin{array}{l}\text { During } \\
\text { campaign } \\
\text { ( } n=177)\end{array}$} & \multirow[b]{2}{*}{ Test statistic } \\
\hline & \# & $\%$ & \# & $\%$ & \\
\hline \multicolumn{6}{|l|}{ Gender } \\
\hline Male & 85 & 81.0 & 157 & 92.4 & \multirow[t]{2}{*}{$P=.01, \nu=0.2$} \\
\hline Female & 20 & 19.0 & 13 & 7.6 & \\
\hline \multicolumn{6}{|l|}{ Age } \\
\hline $15-19$ years & 6 & 5.9 & 5 & 3.1 & \multirow[t]{6}{*}{ n.s. } \\
\hline 20-29 years & 22 & 21.6 & 32 & 19.9 & \\
\hline 30-39 years & 37 & 36.3 & 58 & 36.0 & \\
\hline $40-49$ years & 22 & 21.6 & 52 & 32.3 & \\
\hline $50-59$ years & 10 & 9.8 & 12 & 7.5 & \\
\hline 60 years and over & 5 & 4.9 & 2 & 1.2 & \\
\hline \multicolumn{6}{|l|}{ Activity } \\
\hline Rock fishing & 82 & 78.1 & 145 & 85.8 & \multirow[t]{4}{*}{$P=.01, \nu=0.2$} \\
\hline Walking on rocks & 3 & 2.9 & 11 & 6.5 & \\
\hline $\begin{array}{l}\text { Accompanying } \\
\text { rock fisher }^{\mathrm{a}}\end{array}$ & 18 & 17.1 & 8 & 4.7 & \\
\hline Other & 2 & 1.9 & 5 & 3.0 & \\
\hline
\end{tabular}

Note: n.s. - not statistically significant; discrepancies of totals to sample size due to missing data.

${ }^{a}$ For persons accompanying rock fishers, $65 \%$ were females.

\subsection{Rock fisher behaviours}

Table 4 lists rock fisher self-reported behaviours collected near rock platforms. The majority had been rock fishing 2-5 times in the previous 12 months, owned rock fishing equipment, did not usually fish alone, would swim away from rocks if washed into the water and did not know anyone previously washed off rocks. For the combined sample, 39.2\% reported swimming ability limited to floating $<15$-minutes and swimming short distances. No statistical differences were found between pre- and during campaign. For duringcampaign only on listed measures (Table 4), no statistical differences were found between campaign years or between those recalling safety campaign information and others.

The online survey captured self-reported behaviours associated with key campaign messages for rock fishers during-campaign ( $n=223$ ). Over two-thirds $(66.8 \%)$ reported not always wearing a lifejacket (within this grouping $31.8 \%$ reported never wearing a lifejacket); $93.3 \%$ rock fished alone (6.7\% exclusively rock fished alone) and $95.1 \%$ checked weather conditions before fishing (65.9\% always checked weather conditions).

Comparable to the online survey, self-report data collected at rock platforms are reported in Table 5. For the combined sample ( $N=58$ ), lifejacket wear was infrequent with $60.3 \%$ of a combined sample never wearing a lifejacket and $10.3 \%$ always wearing a lifejacket. Checking weather or surf conditions each time fishing was undertaken by $87.9 \%$. Approximately one-quarter of rock fishers reported fishing alone (26.3\%). For other reported behaviours, most respondents indicated safe approaches taken for fishing preparation or engagement.

Two statistically significant differences between pre- and during campaign indicated for the latter grouping a relatively higher proportion fished alone and failed to wear nonslip shoes. No statistical differences on Table 5 measures were detected for the duringcampaign grouping between campaign years 1 and 2 . Rock fishers able to recall safety information more frequently planned an escape route relative to others $(P<.05, d=0.9)$, but no other statistical differences were found on Table 5 listed measures for this subgrouping comparison.

Rock fisher safety behaviours observed directly on rock platforms are listed in Table 6. Statistical difference pre- and during campaign were found for wearing nonslip footwear and turning one's back to the sea. In both cases, a higher proportion pre-campaign exhibited safer behaviours. For combined samples, observed lifejacket wear was low (2.5\%).

Additional data from observations were recorded. Mean (SD) persons per rock fishing party, estimated from group interactions or arrival patterns pre-campaign were 2.8 (1.1) and during campaign were 2.9 (1.1) with this difference not statistically significant. For rock fishers observed at arrival, mean time in minutes checking conditions before set-up were 7.0 (3.2) and 7.4 (4.8) pre- and during campaign with difference not significant. Distance from the water's edge while fishing pre- $(n=105)$ and during campaign $(n=155)$ was 2.7 (1.4) and 2.4 (1.1) metres, respectively (no statistical difference). 


\begin{tabular}{|c|c|c|c|}
\hline Attitudes associated with rock fishing safety & $\begin{array}{l}\text { Pre-campaign } \\
(n=27) \\
\text { Mean (SD) }\end{array}$ & 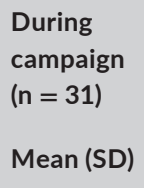 & Test statistic \\
\hline $\begin{array}{l}\text { If someone I knew was going rock fishing I } \\
\text { would recommend they wear a lifejacket }\end{array}$ & $3.8(1.0)$ & $3.8(1.0)$ & n.s. \\
\hline $\begin{array}{l}\text { You should never go to the foreshore, } \\
\text { beaches, cliffs or rocky outcrops alone }\end{array}$ & $4.0(1.0)$ & $3.9(1.0)$ & n.s. \\
\hline $\begin{array}{l}\text { It is important to check surf, tides and } \\
\text { weather conditions before visiting } \\
\text { the foreshore, beaches, cliffs or rocky } \\
\text { outcrops }\end{array}$ & $4.6(0.6)$ & $4.4(0.7)$ & n.s. \\
\hline $\begin{array}{l}\text { Getting swept off rocks while fishing is likely } \\
\text { to result in drowning }\end{array}$ & $4.0(0.7)$ & $3.9(1.0)$ & n.s. \\
\hline $\begin{array}{l}\text { You should always tell someone you are } \\
\text { visiting the foreshore, beaches, cliffs or } \\
\text { rocky outcrops }\end{array}$ & $4.1(0.6)$ & $4.2(0.6)$ & n.s. \\
\hline Rock fishing is a dangerous sport & $3.9(0.9)$ & $3.9(1.0)$ & n.s. \\
\hline $\begin{array}{l}\text { Rock fishing is no more risky than other water } \\
\text { activities }\end{array}$ & $2.7(1.1)$ & $3.1(1.3)$ & n.s. \\
\hline $\begin{array}{l}\text { If you go rock fishing, it is likely that you will } \\
\text { be swept into the ocean }\end{array}$ & $2.7(1.1)$ & $2.8(1.2)$ & n.s. \\
\hline
\end{tabular}

TABLE 3 Self-reported frequency of rock fisher safety attitudes on rock platforms $(n=58)$

Note: n.s. - not statistically significant; Scale: 1 (strongly disagree); 2 (disagree); 3 (neutral); 4

(agree); 5 (strongly agree).

Reasons for rock fishers turning their back to the sea were recorded by observers during-campaign only $(n=128)$. These were to check tackle/equipment (46.1\%); talk to others (25.8\%); move away from water (7.0\%) and other or multiple reasons (21.1\%).

\section{4 | DISCUSSION}

This study reports rock fisher behaviours using direct observation methods. Recent comparable methods have employed novel designs applying direct observation, concealed video footage, GIS data, sketch maps and self-reported data to uncover how rock fishers may cooperate to reduce risk and transfer safe behaviours. ${ }^{17}$ Other previous work, however, relies chiefly on self-report surveys and interviews ${ }^{13,18-22}$ or reviews of fatal and nonfatal events via coronial investigations. ${ }^{3}$ Direct observation has an advantage over these other methods by providing relatively more objective data through unobtrusive data collection. In addition, direct observation allows comparison to or validation of comparable self-report data.

The public awareness safety campaign evaluated here reached an estimated one in six Victorians. This dispersion highlighted campaign potential for entrenching key safety messages, in crude population terms, among target activity participants. For the specific target (rock fishers), campaign reach appeared low with just half of those surveyed online aware of the campaign. Even fewer recalled key safety messages. Regardless, awareness guarantees neither cognition nor safety behaviour adoption. Data collected at rock platforms support this proposition. Although two-thirds of rock fishers engaged in fishing recalled seeing rock fishing safety advertising or information, no behaviour change elicited by the campaign, except perhaps escape route planning, was detected.

The study highlights that behaviour change, particularly among a predominantly male population, is difficult for CALD and non-CALD communities. Numerous examples of unsuccessful behavioural change interventions indicate that a full range of options should be considered. ${ }^{23}$ A promising strategy is targeted education within communities using local ambassadors. Successful campaigns may require too longer periods and sufficient resources. The evaluated campaign was planned as cost-efficient and of short duration.

The study results nevertheless hold value. New information has been provided on rock fisher profiles, behaviours and attitudes confirmed by complementary independent methods and samples. Rock fishers sampled at Victorian fishing locations were predominantly male, aged under 49 years, born outside of Australia, had experience in the activity and participated with others. Self-reported attitudes indicate high levels of agreement on both awareness of drowning risk inherent in the sport and what constitute appropriate safety behaviours during participation. Documented person, behaviour and attitudinal factors will inform design for future safety campaigns.

\section{1 | Safety behaviours linked to campaign key messages}

The study informs on compliance with key campaign messages, wearing lifejackets, not fishing alone and checking environmental 
TAB LE 4 Self-reported rock fisher behaviours on rock platforms $(n=58)$

\begin{tabular}{|c|c|c|c|c|c|}
\hline & \multicolumn{2}{|c|}{$\begin{array}{l}\text { Pre- } \\
\text { campaign } \\
(n=27)\end{array}$} & \multicolumn{2}{|c|}{$\begin{array}{l}\text { During } \\
\text { campaign } \\
(n=31)\end{array}$} & \multirow[b]{2}{*}{ Test statistic } \\
\hline & $\#$ & $\%$ & $\#$ & $\%$ & \\
\hline \multicolumn{6}{|c|}{ Times rock fishing last 12 months } \\
\hline First time & 3 & 11.1 & 7 & 22.6 & n.s. \\
\hline 2-5 times & 16 & 59.3 & 10 & 32.3 & \\
\hline 6-9 times & 3 & 11.1 & 3 & 9.7 & \\
\hline 10-19 times & 3 & 11.1 & 6 & 19.4 & \\
\hline 20 times or more & 2 & 7.4 & 5 & 16.1 & \\
\hline \multicolumn{6}{|c|}{ Own rock fishing equipment } \\
\hline Yes & 26 & 96.3 & 29 & 96.7 & n.s. \\
\hline No & 1 & 3.7 & 1 & 3.3 & \\
\hline \multicolumn{6}{|l|}{ Usually fish alone } \\
\hline Yes & 2 & 7.4 & 6 & 19.4 & n.s. \\
\hline No & 25 & 92.6 & 25 & 80.6 & \\
\hline \multicolumn{6}{|l|}{ Swimming ability } \\
\hline $\begin{array}{l}\text { Cannot float or } \\
\text { swim }\end{array}$ & 2 & 7.4 & 1 & 3.2 & n.s. \\
\hline $\begin{array}{l}\text { Float over } 1 \mathrm{~min} \\
\text { and swim a } \\
\text { short distance }\end{array}$ & 6 & 22.2 & 13 & 41.9 & \\
\hline $\begin{array}{l}\text { Comfortably float } \\
\text { and swim for } \\
\text { about } 15 \mathrm{~min}\end{array}$ & 11 & 40.7 & 9 & 29.0 & \\
\hline $\begin{array}{l}\text { Comfortably float } \\
\text { and swim for } \\
\text { about } 60 \mathrm{~min}\end{array}$ & 8 & 29.6 & 8 & 25.8 & \\
\hline \multicolumn{6}{|c|}{ Behaviour if washed off rocks } \\
\hline $\begin{array}{l}\text { Float until help } \\
\text { arrives }\end{array}$ & 3 & 11.1 & 4 & 12.9 & n.s. \\
\hline $\begin{array}{l}\text { Swim away from } \\
\text { rocks towards } \\
\text { the beach }\end{array}$ & 13 & 48.1 & 20 & 64.5 & \\
\hline $\begin{array}{l}\text { Swim back to } \\
\text { rocks }\end{array}$ & 8 & 29.6 & 3 & 9.7 & \\
\hline Other behaviour & 3 & 11.1 & 4 & 12.9 & \\
\hline \multicolumn{6}{|c|}{ Know someone washed off rocks - including self } \\
\hline Yes & 4 & 14.8 & 5 & 16.1 & n.s. \\
\hline No & 23 & 85.2 & 26 & 83.9 & \\
\hline
\end{tabular}

Note: n.s. - not statistically significant.

conditions. On rock platforms, fewer than half the sampled fishers reported ever wearing a lifejacket, confirmed by a directly observed $<5 \%$ wear-rate. Aligning with the online survey, a small proportion of fishers reported fishing alone and fewer than one in ten were observed alone on rock platforms. Most rock fishers too reported, and were observed, checking water and weather conditions before beginning the activity.

Rock fishers report compliance with safety behaviours. A majority informed others of plans, carried a mobile phone, used nonslip footwear, wore light clothes and infrequently or never turned their back to the sea. Most claimed a prepared escape plan from the water. Direct observations confirmed high wear-rates for nonslip shoes. Some rock fishers do practice unsafe behaviour where fewer-thanhalf wore light clothing and proportionally, 9 from 10 were observed turning their back to the sea. Being swept off feet by waves was infrequently reported. Direct observations confirmed rock fisher low expectations for water entry as most lacked ready-to-use flotation devices including lifejackets.

Through multiple methods, the study identified a disconnection between safety attitudes and behaviours. Although most rock fishers understand suitable responses to drowning risks, this appears to not transfer as safe rock fishing behaviours, particularly regarding lifejacket wear. The complexity of rock fisher risk perceptions were evident where a majority surveyed at a platform agreed rock fishing to be a dangerous sport though many considered this no more risky that other water activities. Many too did not deem it likely to be swept from platform to ocean (Table 3). This safety judgement is likely reinforced where approximately just one in ten rock fishers had experienced a person washed off rocks. Risk may be misjudged too where swell size, water temperature and visibility from adverse weather change by day and season.

The campaign's apparent failure to change both attitudes and behaviour suggests ongoing and perhaps new safety strategies are required. Effective drowning countermeasures may be informed through improved understanding of rock fisher risk perception and decision making. A lack of experience with rock fishing, including in Australian conditions, may further exacerbate drowning risk and so warrant consideration. The limited campaign reach to at-risk persons, including those from CALD backgrounds, supports development of new and targeted communication strategies.

\section{2 | Lifejackets as a key drowning intervention}

From rock fisher reports, the New Zealand 10-year West Coast Fisher Safety Project found a 10-fold increase in lifejacket wear (2006, 4\%; 2015, 40\%). ${ }^{13}$ This effect resulted, presumably, from on-site safety education supplemented by media promotion and static displays. Additional safety advice was provided on-site by trained field officers. The campaign evaluated here was comparable in design to that for New Zealand, excepting provision of trained field officers due to platform remoteness and safety issues with access. Stark differences in lifejacket wear rates between the campaigns may be explained by one or more factors; these being absence of trained field officers, relative campaign reach and duration, divergence in study methods, disparate social desirability bias effects, sampling error or other nonmeasured effects. Nonetheless, direct observation used for this evaluation study provided a reliable measure to confirm the true situation for Victoria.

Apart from risk misperception and associated expectations, reasons for rock fisher failure to wear lifejackets may be cost, inconvenience, discomfort, functionality, prevailing norms or image. This may be influenced by limited knowledge of suitable options 


\begin{tabular}{|c|c|c|c|}
\hline $\begin{array}{l}\text { When rock fishing, how often } \\
\text { do you ... }\end{array}$ & $\begin{array}{l}\text { Pre-campaign } \\
(n=27) \\
\text { Mean (SD) }\end{array}$ & $\begin{array}{l}\text { During campaign } \\
(\mathrm{n}=31) \\
\text { Mean (SD) }\end{array}$ & Test statistic \\
\hline Wear a lifejacket & $2.0(1.5)$ & $1.9(1.3)$ & n.s. \\
\hline Go alone & $1.1(0.3)$ & $1.7(1.1)$ & $P<.01, d=0.7$ \\
\hline $\begin{array}{c}\text { Check weather or surf } \\
\text { warnings }\end{array}$ & $4.9(0.3)$ & $4.7(0.6)$ & n.s. \\
\hline Tell someone of plans & $4.7(0.8)$ & $5.0(0.2)$ & n.s. \\
\hline Wear nonslip footwear & $4.8(0.7)$ & $3.7(1.8)$ & $P<.01, d=0.8$ \\
\hline Wear light clothes & $3.8(1.4)$ & $3.7(1.7)$ & n.s. \\
\hline Have a mobile phone & $5.0(0.2)$ & $5.0(0.2)$ & n.s. \\
\hline Plan an escape route & $3.2(1.8)$ & $3.4(1.9)$ & n.s. \\
\hline Bring a rope or float & $2.4(1.7)$ & $2.3(1.8)$ & n.s. \\
\hline Turn back to sea & $1.7(1.0)$ & $1.9(1.4)$ & n.s. \\
\hline Get swept off feet by waves & $1.4(0.8)$ & $1.2(0.4)$ & n.s. \\
\hline
\end{tabular}

TABLE 5 Self-reported frequency of rock fisher safety behaviours on rock platforms $(n=58)$

Note: n.s. - not statistically significant; Scale: 1 (never); 2 (some of the time); 3 (about half of the time); 4 (most of the time); 5 (always).

available in the marketplace. Given this, more specific marketing may be required to encourage lifejacket use. In Victoria and other jurisdictions, boat users are required to wear lifejackets. Comparable requirements for lifejacket wear among rock fishers may prove the most effective strategy to raise wear-rates.

A New South Wales (NSW) 2015 coronial inquest into nine rock fisher deaths found education and safety advice alone to be insufficient measures for drowning prevention. ${ }^{24} \mathrm{NSW}$ subsequently introduced the Rock Fishing Safety Act 2016 making mandatory use of lifejackets for rock fishers at declared high risk locations. ${ }^{25}$ The effectiveness of this strategy requires assessment. At the time of writing, Victoria is implementing a comparable trial for local rock fishers from March 2022. ${ }^{26}$

\section{3 | Methodological contribution to evaluation studies}

Although no substantive campaign effect on safety was detected in the evaluation, a contribution to the evaluation field is evident through application of comparable data collection methods. The study design allowed for safety behaviour cross-validation from online self-report, onsite self-report and direct observation. Lifejacket wear rates, for example, were found far lower for observed rock fishers relative to self-reports. Moreover, wear rates were claimed as even higher when measured distant from the activity (eg online). Explanations for discrepancies between data collections may reside with sampling error or population differences. More likely though is that collections taken during fishing activities better represent the true situation. Accuracy may be gained on-site through better recall, reduced social desirability bias or the presence of data collectors. In any case, direct observation results with defined confidence level likely provide close to a gold standard representation of lifejacket wear rates, whereas self-report studies overstate this occurrence.
To build on the study results, observation enhancing technologies such as drone surveillance and remote positioned cameras may offer a superior and cost-effective choice for recording observable behaviours. $^{27}$

\subsection{Implications for future safety campaigns and further research}

Communications in multiple languages (Cantonese, English, Mandarin, Vietnamese - inclusive of Simplified Chinese for questionnaires) supported the rock fishing safety campaign, yet reach was limited for the target audience. Future campaigns may require innovative or novel design over longer duration to both capture attention and change rock fisher attitudes and behaviours. Critical here is to understand patterns of media and consumer consumption practiced by the target audience. Novel strategies may involve partnerships with fishing tackle or bait retail outlets, use of social influencers, innovative publicity, ambassadors, and onsite communication. The study indicates regardless that new countermeasures are needed, perhaps developed within an ongoing state-wide strategic plan for rock fishing safety. Messages targeting behaviour norms and drowning impact on families may too be persuasive, though any future strategies require careful evaluation.

Affecting behaviour change is difficult in hard-to-reach populations. CALD communities engender a range of cultural values, practices and attitudes meaning that effective campaigns require a level of nuance and tailoring that attracts additional resourcing. Furthermore, many rock fishers engage irregularly in the activity. And although mandatory regulation of safety practices may be effective for most, monitoring compliance may encourage those rock fishers unwilling to wear, say, lifejackets to seek out more remote and dangerous rock locations to avoid detection.

For rock fishers generally, emotional appeals focussed on sentiments and graphic depictions may drive behavioural change. 
TABLE 6 Observed safety-related behaviours on rock platforms $(n=282)$

\begin{tabular}{|c|c|c|c|c|c|}
\hline & \multicolumn{2}{|c|}{$\begin{array}{l}\text { Pre-campaign } \\
(\mathrm{n}=105)\end{array}$} & \multicolumn{2}{|c|}{$\begin{array}{l}\text { During campaign } \\
\text { ( } \mathrm{n}=177)\end{array}$} & \multirow[b]{2}{*}{ Test statistic } \\
\hline & $\#$ & $\%$ & $\#$ & $\%$ & \\
\hline \multicolumn{6}{|c|}{ Wearing lifejacket } \\
\hline Yes & 5 & 4.9 & 2 & 1.2 & n.s. \\
\hline No & 98 & 95.1 & 166 & 98.8 & \\
\hline \multicolumn{6}{|c|}{ Fishing alone } \\
\hline Yes & 14 & 13.6 & 12 & 7.1 & n.s. \\
\hline No & 89 & 86.4 & 157 & 92.9 & \\
\hline \multicolumn{6}{|c|}{ Check conditions on arrival } \\
\hline Yes & 28 & 66.7 & 22 & 84.6 & n.s. \\
\hline No & 14 & 33.3 & 4 & 15.4 & \\
\hline \multicolumn{6}{|c|}{ Wearing nonslip footwear } \\
\hline Yes & 79 & 78.2 & 76 & 48.7 & $P<.01, \nu=0.3$ \\
\hline No & 22 & 21.8 & 80 & 51.3 & \\
\hline \multicolumn{6}{|c|}{ Wearing light clothes } \\
\hline Yes & 37 & 35.9 & 67 & 40.4 & n.s. \\
\hline No & 66 & 64.1 & 99 & 59.6 & \\
\hline \multicolumn{6}{|c|}{$\begin{array}{c}\text { Turn back to } \\
\text { the sea }\end{array}$} \\
\hline Yes & 82 & 89.1 & 139 & 98.6 & $P<.01, \nu=0.2$ \\
\hline No & 10 & 10.9 & 2 & 1.4 & \\
\hline \multicolumn{6}{|c|}{ Has a floatation device ${ }^{a}$} \\
\hline Yes & 20 & 24.4 & 33 & 27.7 & n.s. \\
\hline No & 62 & 75.6 & 86 & 72.3 & \\
\hline
\end{tabular}

Note: n.s. - not statistically significant; discrepancies of totals to sample size due to missing data.

${ }^{a}$ Includes bucket or insulated container.

Nonetheless, extreme images or scare tactics may be counterproductive. ${ }^{28,29}$ Another campaign avenue noted earlier is through the use of ambassadors and role models. ${ }^{11}$ Although ambassadors were used in the current campaign this was not extensive due to limited resourcing. Rock fishing safety ambassadors and volunteer educators have the capacity to share learnings and educate others on safe practices and influence safety attitudes. This initiative is likely more effective where representatives are experienced rock fishers and relatable to participants (eg by age and cultural background). ${ }^{11}$ In Australia, research is lacking on ambassador impact for rock fisher behaviour change regarding lifejacket wear-rates. For boating, a comparable United States study found lifejacket wearing was associated with the combination of legislation and adult role models. ${ }^{30}$

\subsection{Study limitations and further research}

Multiple methods and samples employed in the evaluation each carry limitations. Regarding representation, online panel data were collected in a purposeful manner negating random assignment. Data collected near rocky platforms occurred typically during good fishing conditions, introducing unknown bias through sampling error. Direct observations were made at a distance from the fishing sites, and though assisted by powerful binoculars, errors were possible in recording data including the assumption of checking conditions and footwear type. As earlier mentioned, self-reported data may be biased from eliciting socially desirable responses. Testing group differences relied often on small sample sizes. On-site too, high rates of self-report refusals were noted raising additional possible bias. Reasons were not provided but presumably refusals were due to rock fishers being in transit to or from the activity and so unwilling to stop. As noted, no postcampaign evaluation was undertaken due in part to continuation of campaign elements including ongoing rock fisher safety messaging facilitated by Life Saving Victoria.

Study findings and inherent limitations raise avenues for further research. For example, the effect on subsequent safety behaviours of "close calls" following unintentional water entry is unknown. Further work on risk perceptions may highlight how rock fishers judge conditions and the impact of experience. ${ }^{17} \mathrm{~A}$ key question concerns barriers to wearing lifejackets which may involve factors including cultural norms and cost. ${ }^{31}$ Better understanding of rock fisher archetypes as influenced by motivations, whether these be related to consumption, escape, relaxation, challenge and so on may assist to understand behaviours and better target interventions. Qualitative methods well-placed to meet these research needs.

\subsection{Recommendations}

Based on study findings evaluating a rock fishing campaign in Victoria, six recommendations are suggested:

1. Review the impact of NSW legislation on mandatory lifejacket use to inform on and compare those being introduced for rock fishers in Victoria.

2. Assess interactions between rock fisher behaviours and environmental factors focussing on hazard perceptions of swell heights and wave overtopping.

3. Measure the efficacy of CALD role models including ambassadors or trained field officers in delivering safety information to rock fishers.

4. Evaluate effects from emotive-style safety messages and message delivery by referent groups including police and fishing organisations.

5. Conduct further epidemiological studies of rock fishers to determine the risk factor contribution and interactions in drowning.

6. Consider using new technology (eg, drones, cameras) to evaluate public awareness strategies promoting rock fisher behavioural change. 


\section{5 | CONCLUSION}

Rock fishing is a popular and potentially dangerous sport. In reducing drowning risk, authorities face challenges designing effective safety strategies. Key risk factors involving environmental hazard perceptions and lifejacket wear require further understanding to support novel and tailored drowning countermeasures. Promising options are available including use of technology assisted surveillance. For this evaluation, discrepancies between self-report behaviours and direct observations show the latter imperative for subsequent evaluation research on rock fishers. Regardless, legal enforcement of lifejacket wear appears a viable method as part of a multifactorial strategy to reduce drowning fatalities by behavioural change, though further assessment is required to provide a sound evidence-base for effectiveness of planned interventions.

\section{ACKNOWLEDGMENTS}

The authors gratefully acknowledge the study participants, VRFish and Fisheries Victoria (now the Victorian Fishing Authority) and Victoria Police. Open access publishing facilitated by James Cook University, as part of the Wiley - James Cook University agreement via the Council of Australian University Librarians.

\section{CONFLICT OF INTEREST}

The authors confirm that there is no financial or other substantive conflict of interest noted.

\section{ETHICS APPROVAL}

This study was conducted with Human Ethics Certificate of Approval granted by the Monash University Human Research Ethics Committee (MUHREC). Project Number: CF13/276 - 2013000113, issued 18 February 2013. The study was approved subsequently by the Federation University Human Research Ethics Committees - Project E14-015.

\section{ORCID}

Rhiannon Birch (D) https://orcid.org/0000-0002-1783-8673

Damian Morgan (D) https://orcid.org/0000-0002-2811-2720

Bernadette Matthews (D) https://orcid.org/0000-0002-6258-2961

\section{REFERENCES}

1. Kennedy DM, Sherker S, Brighton B, Weir A, Woodroffe CD. Rocky coast hazards and public safety: moving beyond the beach in coastal risk management. Ocean Coast Manag. 2013;82:85-94.

2. Peden AE, Scarr J-P, Mahony AJ. Analysis of fatal unintentional drowning in Australia 2008-2020: implications for the Australian Water Safety Strategy. Aust N Z J Public Health. 2021;45(3):248-54.

3. Jones $M$. Investigation into the coronial files of rock fishing fatalities that have occurred in NSW between 1992 and 2000. New South Wales: Safe Waters, NSW Water Safety Taskforce; 2003.

4. Ryan A, Rijksen E, Stone K, Daw S. Coastal safety brief: rock fishing. Sydney: Surf Life Saving Australia; 2018.
5. Clapperton A, Cassell E A national review of rock fishing deaths and hospital-treated injury. Melbourne, Australia: Monash University; 2011.

6. Royal Life Saving Society - Australia. National Drowning Report 2011. Sydney: Royal Life Saving Society - Australia; 2011.

7. Quan L, Bennett EE, Branche CM, Interventions to prevent drowning, In: L.S. Doll, Bonzo S.E., Sleet D.A., Mercy J.A. editors, Handbook of injury and violence prevention. Boston, MA: Springer US; 2007. p. 81-96.

8. Marine Safety Regulations S R. No. 45/2012. Vic.: d. 4. Available from https://content.legislation.vic.gov.au/sites/default/files/ 2020-07/12-45sra011\%20authorised_1.pdf

9. Coroner's Court of Victoria. Finding into death with inquest Court Ref: 3741/09, 5959/2009, 6036/2009. Victoria: Coroner's Court of Victoria; 2011.

10. Bradstreet A, et al. Research review of rock fishing in New South Wales. Sydney: Surf Life Saving Australia; 2012.

11. Mitchell R, Ware L, Bambach MR. The role of evidence, standards and education in rock fishing safety in New South Wales, Australia. Aust N Z J Public Health. 2014;38(6):579-84.

12. Peden $A E$, Demant $D$, Hagger MS, Hamilton K. Personal, social, and environmental factors associated with lifejacket wear in adults and children: A systematic literature review. PLoS One. 2018;13(5):e0196421.

13. Moran K. Rock-based fisher safety promotion: a decade on. Int J Aquat Res Educ. 2017;10(2):1.

14. Australian Bureau of Statistics. Australian demographic statistics, Dec 2018. Cat. No. 3101.0. Canberra: Australian Bureau of Statistics; 2018.

15. IBM. IBM SPSS statistics version 22. Armonk, NY: IBM Corp.; 2013.

16. Lowry R VassarStats [online statistical calculator]. 2017 [cited 30 September 2017]. Available from: http://vassarstats.net

17. Kamstra P, Cook B, Edensor T, Kennedy D, Kearnes M. Relational risk and collective management: a pathway to transformational risk management. Risk Anal. 2021;41(10):1782-94.

18. Jasper R, Stewart BA, Knight A. Behaviours and attitudes of recreational fishers toward safety at a 'blackspot' for fishing fatalities in Western Australia. Health Promot J Austr. 2017;28(2):156-9.

19. Kamstra P, Cook B, Kennedy DM, Brighton B Treating risk as relational on shore platforms and implications for public safety on microtidal rocky coasts. Nat Hazards. 2018;91(3):1299-316.

20. Mitchell R, Haddrill K. Working in partnership with the Chinese community in NSW to develop appropriate strategies to target water safety. Health Promot J Austr. 2004;15(1):38-43.

21. Moran K. Rock-based fishers' perceptions and practice of water safety. Int J A'quat Res Educ. 2008;2(2):13.

22. Moran K. Rock-based fisher safety promotion: five years on. Int J Aquat Res Educ. 2011;5(2):164-73.

23. Michie S, van Stralen MM, West R. The behaviour change wheel: a new method for characterising and designing behaviour change interventions. Implement Sci. 2011;6(1):42.

24. Coroners Court of New South Wales. Inquest into the deaths of Myassar Ayoub (File No 2012/224038); Donald White (File No 2012/341729); Zheng Wang (File No 2012/351532); Sung Su Cho (File No 2014/178522); Greg Walter Reardon (File No 2014/3934); Huiqing Hua (File No. 2014/126091); Ding Ding Zhang (File No 2014/166145); Young Whan Kim (File No 2014/248856); Jesse Jack Howes (File No 2015/35662). 2015: Coroners Court, Glebe

25. New South Wales Government. Rock Fishing Safety Act No 66, 2016, in Act No 66, 2016. New South Wales Government; 2016.

26. Victorian Fisheries Authority. Rock fishing safety. 2021 [cited 2021 23 November]. Available from: https://vfa.vic.gov.au/recreationalfishing/rock-fishing-safety

27. Morgan D. Counting beach visitors: tools, methods and management applications. In Beach management tools-concepts, methodologies and case studies. Springer; 2018. p. 561-77. 
28. Dunstone K, Brennan E, Slater MD, Dixon HG, Durkin SJ, Pettigrew $S$, et al. Alcohol harm reduction advertisements: a content analysis of topic, objective, emotional tone, execution and target audience. BMC Public Health. 2017;17(1):312.

29. Wundersitz L, Hutchinson T, Woolley J. Best practice in road safety mass media campaigns: a literature review. Soc Psychol. 2010;5:119-86.

30. Chung C, Quan L, Bennett E, Kernic MA, Ebel BE. Informing policy on open water drowning prevention: an observational survey of life jacket use in Washington state. Injury Prev. 2014;20(4): 238-43.

31. Cox KL, Bhaumik S, Gupta M, Jagnoor J. Facilitators and barriers of life jacket use for drowning prevention: qualitative evidence synthesis. J Safety Res. 2021.

\section{SUPPORTING INFORMATION}

Additional supporting information may be found in the online version of the article at the publisher's website.

How to cite this article: Birch R, Morgan D, Arch J, Matthews B. Rock fisher behaviours and perceptions regarding drowning risk assessed by direct observation and self-report: A public awareness campaign evaluation. Health Promot J Austral. 2022;00:1-11. https://doi.org/10.1002/hpja.583 